\title{
Research
}

\section{What You Know is Who You Know? Communication Patterns Among Resource Users as a Prerequisite for Co-management}

\author{
Beatrice Crona $^{1}$ and $\underline{\text { Öjan Bodin }}^{1}$
}

\begin{abstract}
The social networks is one factor determining the flow of information within communities and as such may be important in determining successful implementation of community based management. We mapped the social network used for communication of knowledge and information related to natural resource extraction among villagers in a coastal seascape in Kenya. We further identified subgroups and examined their interrelations while measuring to what extent personal attributes such as occupation can explain observed group structure. Finally, we compared the local ecological knowledge held by villagers of different occupations with the structure of the communication network to map how well this structure can explain distribution of ecological knowledge among them. Results show that communication occurs primarily between fishermen who use the same gear type, which may inhibit exchange of ecological knowledge within the community. This may partly explain why the community has been unsuccessful in regulating resource extraction, especially since potentially influential groups of nonfishermen have a limited communication with the various fisher groups. Analysis of network structure also shows that groups most central, and hence potentially most influential, are dominated in numbers by migrant deep sea fishermen, hypothetically less motivated to initiate collective action for resource management. Hence, we conclude that a lack of collective action to remedy an unsustainable situation may be attributed to various different but distinct aspects of the specific structure of the social network.
\end{abstract}

Key Words: co-management; communication patterns; East Africa; ecological knowledge; fisheries; fishing gear; social networks.

\section{INTRODUCTION}

The idea that natural systems are dynamic and inherently unpredictable is becoming increasingly established (Carpenter et al. 2001, Scheffer et al. 2001, Folke et al. 2004). Along with this, there is an emerging recognition that to effectively manage such uncertainty requires adaptive approaches and a system of continuous learning to interpret and respond to ecological feedback (Walker et al. 2002, Olsson 2004a). It is also well known that many communities of resource users possess intricate knowledge of their local resource base (Johannes 1981, Hunn et al. 2003, Ghimire et al. 2004), and that such local ecological knowledge (LEK) can provide a valuable base for resource management (Johannes 1998, Becker and Ghimire 2003, Moller et al. 2004).
A management system that embraces adaptability and explicitly emphasizes the importance of the resource users' LEK is embodied in the concept of adaptive co-management (Gadgil et al. 2000). It combines the element of dynamic learning in adaptive management (e.g., Holling 1978) with collaborative management, (e.g., Buck et al. 2001) linking groups of stakeholders for the joint management of resources (Olsson 2004a). However, for adaptive co-management to work, self-organization of stakeholders and collective action have also been suggested as vitally important (Olsson 2004a), and this in turn is influenced by the ability of the involved parties to agree on resource related problems and resource status (see Ostrom 2005 and references therein).

Communities are rarely just one single group of local stakeholders; rather, they are defined by 
complicated patterns of subgroups with different perceptions, interests, resources, and amounts of influence (Carlsson and Berkes 2005, Nygren 2005). Furthermore, social psychologists and sociologist have long argued that individuals are most influenced by the people with whom they engage in frequent interactions, i.e., their primary groups (Cooley 1909, Festinger et al. 1950, Homans 1950, Kadushin 1966). This implies that individuals are likely to develop an understanding of the status of a natural resource similar to other members of the same stakeholder group. Hence, it should not be presumed that the scale and content of LEK are uniformly distributed among resource users in a community. In fact, knowledge of ecological functions and processes may vary among groups of resource users as demonstrated by several studies (Hunn et al. 2003, Ghimire et al. 2004, Crona 2006).

If we assume that a reasonable level of mutual understanding of resource status increases the likelihood that stakeholders will organize and agree upon common rules for managing the resource (see Ostrom 2005 and references therein), then enabling members of different stakeholder groups to establish such a common understanding through intergroup relations, in the form of bridging ties, is crucial (e.g., Schneider et al. 2003). Hence, exchange of information and knowledge among stakeholder groups emerge as fundamental elements in the successful management of natural resources. The existences of such bridging ties are, in addition, thought to be important for the community's potential for collective action (Granovetter 1973) and conflict resolution (e.g., Carlsson and Berkes 2005). In this sense, the structural characteristics of the social network of individuals and groups in a community influence the potential for successful natural resource management by its profound effect on the diffusion of information and knowledge; and therefore, indirectly, on the distribution and variability of LEK among users (cf., Weimann 1982, Gould and Fernandez 1989, Abrahamson and Rosenkopf 1997, Reagans and McEvily 2003).

In this study, we mapped the social network used for communication of knowledge and information related to natural resources among different professionals and resource extractors operating in a coastal seascape in Kenya. This community was chosen as it has not been successful in regulating the inshore local fishery, a problem that has led to a system currently diagnosed as overexploited
(McClanahan et al. 1997, Ochiewo 2004). Our objective was to investigate if lack of collective action to remedy this unsustainable situation may be attributed to the structures of the social networks in the community. The underlying assumption is that the distribution of LEK in the community, which is dependent on the network structure, affects the likelihood that the community will reach a common understanding of resource-related problems at hand. This, in turn, affects their ability to selforganize around regulations of resource extraction.

To map the interaction patterns related to the exchange of information and knowledge of natural resources among individuals in the community, we used methods from the social sciences with emphasis on the field of social network analysis (SNA) (see e.g., Wasserman and Faust 1994, Scott 2000). This provided us with a toolbox to quantify various theoretically important structural characteristics of the social network. Using network analysis, we set out to test two hypotheses:

1. Occupation, and more specifically the geardefined fishing technique among fishermen, is important in defining group membership in the community in relation to communication of resource-related information.

2. Social network structure can explain the distribution of common and group specific ecological knowledge among user groups. More specifically, groups with strong links between each other tend to have similar knowledge, in this case LEK.

Finally, we discuss the implications of our findings for adaptive co-management in the study area. We also present some hypotheses, using social theories that link network structure to social phenomena, on why the focus community has not succeeded in regulating their resource extraction. To our knowledge, this study is one of the first attempting to use a quantitative analysis of empirical social relational data in research on adaptive comanagement of natural resources. 


\section{METHOD}

\section{Area description}

The area of focus in this study is a rural fishing village located $\sim 50 \mathrm{~km}$ south of Mombasa in Kenya (Fig. 1). It has 200 households and an estimated 1000 inhabitants. The ecological system is characterized by mangroves covering $\sim 5 \mathrm{~km}^{2}$, with mudflats and seagrass meadows in the shallow part of the bay. The lagoon is sheltered from intense wave impact by shallow reefs at the mouth of the bay (Fig. 2). The use of resources in the village is centered on fishing, and to some degree the use of mangroves for poles and firewood. Other nonforest products are also taken from mangroves, but government restrictions in the form of a cutting ban have periodically impeded extraction of wood products by locals (Dahdouh-Guebas et al. 2000). A majority of the households depend primarily on fishing for their livelihoods, whereas farming and small-scale businesses represent some alternative livelihoods. The artisanal fishery is based on gear such as seine nets, different types of gillnets, spearguns, handlines, and, to a lesser extent, traps. These methods are spatially separated on a local geographical basis (Fig. 2 and Obura et al. 2002), a feature also found in other artisanal fisheries (Johannes 1981).

\section{Data collection}

The target population was defined as all households resident in the village for at least 6 mo prior to data collection, and constituted 206 households. Social network data was compiled by questionnaires completed through personal interviews with heads of households to identify social ties. A nearly complete, i.e., $83 \%$, network data set was gathered based on interviews with the heads of 171 households, resulting in $\sim 1500$ reported relations in total. Data on various types of ties were collected to investigate a number of different social networks, such as social support and gear dependency networks, etc. (Table 1). In this study, only the information/knowledge exchange network relating to the state and extraction of natural resources was used (Questions 4 and 5 in Table 1). Collections of network data included both recognition and recall methods (Marsden 1990, Wasserman and Faust 1994), although only data collected using the recall method were used in this study. Recall methods involved each respondent reporting his/her relations, thus generating a list of persons as well as briefly describing the relation, the type of exchange, and the frequency of interaction. In addition to social relations personal attributes such as gender, age, civil status, clan, tribe, occupation, and residence time in the village, among others, were collected for each respondent. All interactions with respondents were done in Kiswahili.

Data on the LEK held by different occupational categories of resource users was collected through focus groups and individual interviews and is presented in detail in Crona (2006). In addition to local businessmen, farmers, and middlemen, i.e., fishmongers, five occupational categories of fishermen were defined based on primary gear type and fishing technique. These included deep sea, seine net, gill net, handline, and speargun fishermen. Only the former three fishermen categories were used in this analysis, and their group-specific distribution of fishing effort in the seascape is shown in Fig. 2. Detailed descriptions of occupational categories are found in Appendix 1.

In total, 13 groups were interviewed, complemented with 19 individual interviews, over a period of 4 mo in 2004 and 2005. Each group contained between four and six participants, and groups were selected based on interviews with the village chairman and fishermen at the local landing site. In most cases a crew captain was approached and asked to participate along with members of his crew.

As one purpose of the study was to investigate and compare ecological knowledge of occupational categories, a segmented sampling design was used, with replication of each type of group within segments. To compare knowledge among groups in each segment, a semistructured interview guideline was used based on the approach described by Morgan (1998). The discussion focused on two topics: (1) the knowledge of species and ecological processes in the bay, and (2) acknowledgment of changes in the ecosystem over time and understanding of ecological processes and links among components in the system. Knowledge was determined as LEK and was included in the subsequent analysis only if mentioned at least three times by individual groups as suggested by Davis and Wagner (2003). 
Fig. 1. Map of the study area with the target community indicated in the inset of the left hand corner.

The area is located on the southern Kenyan coast at $4^{\circ} 25^{\prime} \mathrm{S}$ and $39^{\circ} 50^{\prime} \mathrm{E}$, approximately $50 \mathrm{~km}$ south of Mombasa.

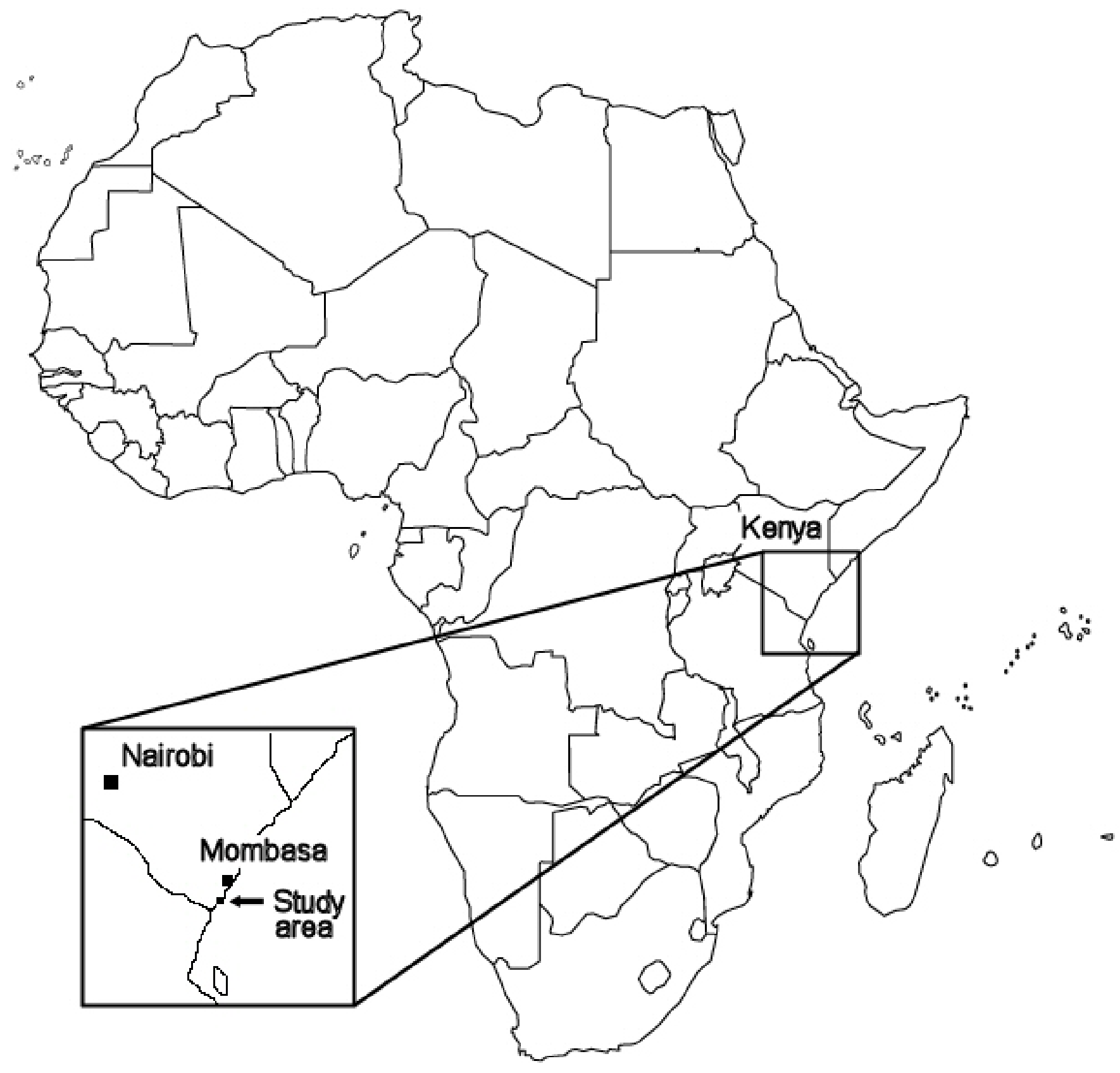


Fig. 2. Map of the coastal seascape in focus. The respective distribution of mangroves, mudflats, seagrass beds, and reefs is indicated. The area of primary fishing effort for each fishing related occupational category is marked with dotted lines showing the geographical distribution of fishing areas at a local scale. The occupational categories associated with each area are indicated in the figure.

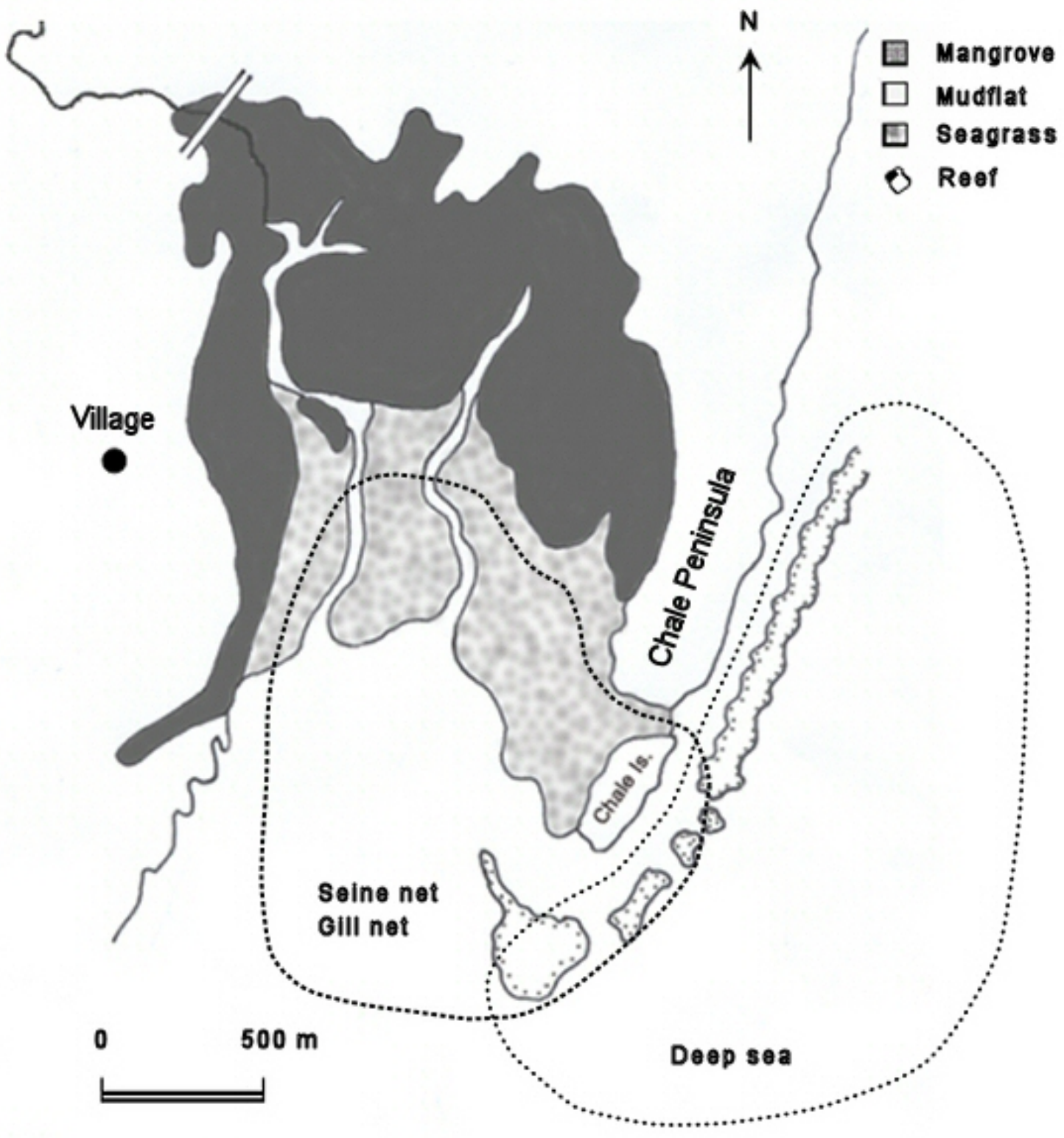


Table 1. Overview of questions put to each respondent for collection of network data.

\begin{tabular}{|c|c|c|c|}
\hline Question Number & Question & Method & Type of relation \\
\hline Q1 & $\begin{array}{l}\text { Personal information regarding age, gender, civil status, } \\
\text { etc. }\end{array}$ & - & \\
\hline Q2 & $\begin{array}{l}\text { Do you have close family outside of \#village name\#? (Y/ } \\
\text { N) If yes, fill in the table below for all close family } \\
\text { members outside of \#village name\#. }\end{array}$ & Recall & External social relations \\
\hline Q3 & $\begin{array}{l}\text { With whom can you discuss important matters? Anything } \\
\text { important to you. List the names in the table below. }\end{array}$ & Recall & Social support \\
\hline Q4 & $\begin{array}{l}\text { If you noticed changes in the natural environment, e.g., } \\
\text { the number of fish caught, the condition of the mangrove } \\
\text { forest or reef, availability of firewood etc., who would } \\
\text { you discuss this with? Name persons in table below. }\end{array}$ & Recall & Information/knowledge exchange \\
\hline Q5 & $\begin{array}{l}\text { Do you exchange information with anyone which is } \\
\text { useful for you to carry out your common occupation? (Y/ } \\
\text { N) If yes, name persons in table below. For example, told } \\
\text { you about practices, good fishing spots, equipment, } \\
\text { timing, and season, etc.? }\end{array}$ & Recall & Information/knowledge exchange \\
\hline Q6 & $\begin{array}{l}\text { Is there any person(s) on whom you depend, or who } \\
\text { depend on you, to carry out your/their occupation? (Y/N) } \\
\text { If yes, name persons in table below, e.g., do you need } \\
\text { someone else's boat, gear, nets, etc. to carry out your } \\
\text { occupation? }\end{array}$ & Recall & Gear dependency \\
\hline Q7 & $\begin{array}{l}\text { In your occupation do you buy and/or sell your goods to } \\
\text { anyone in particular? (Y/N) If yes, name persons in table } \\
\text { below, e.g., do you sell your fish, poles, firewood, } \\
\text { makuti, etc. to a particular person? Or, from who do you } \\
\text { buy bate, nets, etc. If no, see question below. }\end{array}$ & Recall & Economic exchange \\
\hline Q8 & $\begin{array}{l}\text { Do you ever send/receive money or other valuables to/ } \\
\text { from anyone outside of the village? If yes, name person } \\
\text { in table below. }\end{array}$ & Recall & Remittance pathways \\
\hline Q9 & $\begin{array}{l}\text { Have you ever encountered a dispute with anyone related } \\
\text { to your occupation? Specify why and with whom. }\end{array}$ & Recall & Conflict resolution \\
\hline Q10 & $\begin{array}{l}\text { If you encounter a dispute with someone, do you turn to } \\
\text { someone to settle the conflict? If yes, whom? }\end{array}$ & Recall & Conflict resolution \\
\hline Q11 & $\begin{array}{l}\text { If you see that someone is breaking the law within the } \\
\text { area of your occupation, do you tell someone? If so, who? }\end{array}$ & Recall & Conflict resolution \\
\hline Q12 & $\begin{array}{l}\text { Below is a list of } 10 \text { randomly selected individuals from } \\
\text { the village. Based on Questions } 4 \text { and 5, can you to tell us } \\
\text { if you know them? If so do you exchange information } \\
\text { with them and how often, on a scale (1-3)? }\end{array}$ & Recognition & Information/knowledge exchange \\
\hline
\end{tabular}




\section{Analysis}

Methods from the interdisciplinary field of social network analysis (SNA) were used to quantitatively assess structural aspects of the social network (for overview see Wasserman and Faust 1994, Scott 2000, Freeman 2004). To investigate if occupation, i.e., gear-defined occupation for fisherman, are important in structuring communication networks related to natural resources, we defined two kinds of groups in our analyses: (1) groups based on respondents' occupations, i.e., occupational groups; and (2) groups derived solely based on relations reported by the respondents, without taking into account individual attributes such as occupation, i. e., focusing only on the structural pattern of relational groups. Knowledge was treated as a dependent variable, and its distribution among resource users was qualitatively compared to maps of group relations to assess if and how information/ knowledge transfer could explain LEK distributions. Analysis of the knowledge, ideas, and attitudes derived from focus groups were compared based on the two major knowledge topics outlined above and are described further in Crona (2006).

\section{Occupational groups}

For occupational groups, we defined group membership based on occupation and calculated the amount of within-group relations, i.e., the number of social ties between persons of the same occupation, as well as the amount of relations between members of different groups. To analyze relations between occupational groups, a sociomatrix (e.g., Wasserman and Faust 1994) was constructed. The number of relations within and among groups were then compared to the number of relations that would be expected by chance alone, assuming that all relations were distributed randomly without any regard to respondents' occupations. This resulted in a ratio of measured vs. expected relations, calculated using Ucinet (Borgatti et al. 2002). A ratio above 1.0 implies a higher than expected number of reported relations among those particular groups and values below 1.0 lower than expected number of reported relations. By using the hypergeometric probability function in Statistix 8 (Analytical Software, Tallahasse, FL, USA), the likelihood that a calculated ratio in the sociomatrix could have arisen by chance alone could be estimated.
We categorized the strength of an intergroup relation as "strong" if the ratio exceeded 1.0, "medium" if the ratio was between 0.5 and 1.0, and "low" if the ratio was below 0.5. Groups and their relational ties were plotted using a multidimensional scaling (MDS) technique, and position in space was determined by intergroup relations and their strengths (Frank 1996). Groups that had strong intergroup relations, as well as similar patterns of relations to other groups, were positioned close to each other in the MDS plot. Thus, groups at the center of the plot occupy a central social position.

\section{Relational groups}

Relational groups were determined based only on relations reported by respondents. There are numerous methods available to formally divide individuals in a network into different subgroups (Wasserman and Faust 1994, Scott 2000). All methods have emerged from a desire to distinguish subsets of individuals based on the cohesiveness or reachability of group members, as well as on the relative frequency of relations within the subset as compared to relations with nonmembers. We chose the "community structure" (CS) method proposed by Girvan and Newman (2002). Its major difference compared to most other available methods is that CS does not discriminate against peripheral nodes. Whereas nodes with just one link tend to be left out by other methods, CS simply assigns them the same group membership as their neighbor. However, other methods are generally better at finding cores of strongly and/or intensely interlinked individuals (Newman and Girvan 2004), but as our priority was to assign all individuals to appropriate groups, and not only the most interconnected ones, the CS method was suitable.

The CS method produces hierarchically nested groups by incrementally dividing the population into increasingly smaller units until all individuals are assigned to separate groups. Thus, each hierarchical level produces a different set of groups, and requires the analyst to make a choice at which level the most appropriate group division occurs. We used the measure "modularity" suggested by Newman and Girvan (2004) to objectively choose an appropriate hierarchical level. The chosen level represented the one at which the computed modularity reached a maximum. The measure of modularity can also be used as a form of significance test, whereby the values of modularity of the 
observed network are compared to values calculated for randomly generated networks with the same number of nodes and links as the measured network. This allows one to see if values of modularity based on the former are likely to have been obtained if the observed network structure was purely random, without any tendencies for multiple groups. Respondents and their relational ties were plotted using the same multidimensional scaling (MDS) technique as for occupational groups.

To check if occupational category correlated with membership of the relational groups, we applied a chi-square analysis. To account for the sparseness in our cross-tabulation of relational groups and occupational categories, we applied Monte Carlo simulations using StatXact 6 (Cytel Software Corporation, Cambridge, MA, USA) to obtain reliable $P$ values. StatXact 6 also provided us with adjusted standardized residuals (Haberman 1978) for each cell in the cross-tab.

\section{RESULTS}

Quantification of communication and information exchange about natural resources among individuals of the same occupational categories is presented in Table 2 along with the number of individuals of each occupation. Only occupational categories with more than three members were included in this analysis. Occupational categories that were very broadly defined and consequently too heterogeneous to be perceived as coherent categories were also excluded. After exclusions, 116 individuals remained. Analysis showed strong tendencies for within-group communications among all occupational categories except businessmen and, to a lesser extent, farmers (Table 2). Based on the sociomatrix (Table 3), a multidimensional scaling plot (MDS) was generated to show the strength and patterns of communications between occupational categories (Fig. 3). Figure 3 presents the all-encompassing pattern of communication among predefined occupational categories.

In line with our objective to test if fishing technique is important in defining the studied communication networks of this fishing community, we also analyzed group structures based solely on relations reported by respondents in contrast to predefined categories (Fig. 3). There were 47 individuals who did not report any relations with others, nor did others ever report any relations with them. Of the remaining 159 individuals, 155 were part of a single, large network component, i.e., a subnetwork in which it was possible to move between any two nodes using one or several links. This component was further analysed in search of cohesive groups using the Community Structure method (Girvan and Newman 2002). The results in Fig. 4 show cohesive groups as spatially confined clusters of nodes.

To test the likelihood of obtaining the observed relational group structures purely by chance, we generated 100 random networks, assessed all the group structures of these networks using the Community Structure (CS) method, and finally calculated the corresponding modularities (Fig. 5 and Newman and Girvan 2004). The calculated modularities of the observed real-world network were significantly higher than would be expected for a network without multiple group tendencies. This is shown by the clearly demarked curve of modularities for the real-world network in relation to the generated random networks (Fig. 5).

Some groups have markedly lower numbers of relations both internally among group members as well as with members of other groups as compared to other groups (see the periphery of Fig. 4). However, the majority of individuals were assigned to groups in which the density of relations both within and between groups was relatively high. The degree of homogeneity, the tendency for people to have more connections to others of their own kind, was tested through a chi-square analysis and reveals a clear and strong tendency of homogeneity based on occupation, i.e., individuals of the same occupation occurring in the same group (Table 4).

Tables 5 and 6, and Fig. 6, summarize the main differences and similarities between the LEK held by the occupational categories studied. Analysis of LEK revealed discrepancies in terms of the level of detail of knowledge held by farmers and businessmen compared to the majority of resource extractor categories (Fig. 6). The former occupational groups showed consistently poorer knowledge of all coastal habitats as well as a poor understanding of related ecological processes. The LEK held by fishermen of various occupational categories revealed a range, from detailed accounts of feeding of certain target species to acknowledgement of large-scale climatic changes affecting shrimp stocks and mangrove coverage. On a general level, knowledge common to most groups 
Table 2. Distribution of self-reported, within-group relations among occupational groups (Questions 4 and 5 in Table 1). Size refers to the number of individuals within respective occupation, Ratio refers to the ratio of observed vs. expected within-group relations based on an assumed random distribution of all relations, Rel/Ind refers to the total number of reported relations to individuals irrespective of their occupation, divided by the number of members within the group, and Rel/Ind in group refers to the number of reported within-group relations divided by the number of group members. The numbers in parentheses represent the probabilities $(\%)$ of acquiring a higher ratio, assuming independence between the occupational categories and probability for relational ties. For example, for the within-group ratio of businessmen (0.92), the probability of acquiring a higher ratio would be $64 \%$.

\begin{tabular}{|c|c|c|c|c|}
\hline & Size & Ratio obs/exp & Rel/Ind & Rel/Ind in group \\
\hline Seine Net & 16 & $6.13(0.0 \%)$ & 3.1 & 2.0 \\
\hline Businessmen & 27 & $0.92(64 \%)$ & 0.7 & 0.5 \\
\hline Farmer & 8 & $1.64(46 \%)$ & 0.9 & 0.3 \\
\hline Deep Sea & 45 & $2.79(0.0 \%)$ & 3.6 & 2.7 \\
\hline Gill Net & 10 & $9.20(0.0 \%)$ & 3.3 & 1.8 \\
\hline Middleman & 10 & $5.11(0.2 \%)$ & 2.0 & 1.0 \\
\hline Mean value & & & 2.5 & 1.4 \\
\hline
\end{tabular}

included the acknowledgement of the central role played by mangroves for coastal protection, nursery habitat, and water quality (Table 6). The seasonal rains and related freshwater pulse affecting shrimp and fish migrations were also recognized by all categories (Table 6). Group specific knowledge included recognition that sea urchin aggregations can affect the dynamics of seagrass meadows and associated fauna, i.e., seine net, and a notion of regional fish stock migrations related to wind patterns and currents, i.e., middlemen, deep sea, and only to some degree seine net fishermen. Deep-sea fishermen have knowledge of currents and linkages between the three ecosystems in Fig. 6, i.e., mangroves, seagrasses, and reefs, at a scale surpassing that of other fishing groups. In other words, they have a more holistic perception of the seascape as compared with all other groups. In addition, their notion of fish migrations spans a larger geographical scale than seine netters since they acknowledge that pelagic stocks move up and down the coast on a regional scale (Table 5). A more detailed analysis of the LEK inventory is presented in Crona (2006).

\section{DISCUSSION}

\section{Sticking with your own kind}

Homogeneity refers to the tendency for people to have more connections to others than they have to others of their own kind, whether kind is defined by characteristics such as gender, race, social class, or other attributes. Shared social characteristics are presumed to not only reduce conflict, but also facilitate communication due to common background and shared life experience (Reagans and McEvily 2003). Homogeneity is also a factor thought to enhance tacit knowledge transfer (Cross 2001). High levels of homogeneity could, however, reduce diversity and limit access to distant resources (Krackhardt and Stern 1988).

In this study, homogeneity is observed primarily through occupational category. Both the analysis of the network structures based on predefined occupational groups (Fig. 3 and Tables 2 and 3), and the analysis of the relational groups (Fig. 4 and Table 4), shows that occupation is a strong 
Table 3. Occupational group sociomatrix based on information/knowledge exchange network (Table 1). Numbers in cells represent the ratio of the measured vs. the expected number of relational ties.

\begin{tabular}{|c|c|c|c|c|c|c|c|}
\hline & Seine net & Businessmen & Farmer & Deep sea & Gill net & Middleman & $\begin{array}{l}\text { Number of } \\
\text { group members }\end{array}$ \\
\hline Seine net & 6.13 & 0 & 0 & 1.02 & 0 & 0.29 & 16 \\
\hline Businessmen & & 0.92 & 0.21 & 0.19 & 0 & 0 & 27 \\
\hline Farmer & & & 1.64 & 0.13 & 1.15 & 0.58 & 8 \\
\hline Deep sea & & & & 2.79 & 1.23 & 0.72 & 45 \\
\hline Gill net & & & & & 9.20 & 0.46 & 10 \\
\hline Middleman & & & & & & 5.11 & 10 \\
\hline
\end{tabular}

determinant of group cohesion and consequently supports the former division. This indicates that gear-defined occupation does play an important role in defining communication of resource-related knowledge and information in this community. Glaesel (2000) similarly showed gear-defined occupation to be very important for identity politics in other Kenyan fishing communities, indicating that such patterns are likely a more general feature of coastal communities in the area.

\section{Local ecological knowledge (LEK) distribution and network structure}

There is a fair agreement between the distribution and content of local ecological knowledge (LEK) among studied groups and the structure of the social network examined. A qualitative comparison of the network structure (Fig. 3) and the content and distribution of knowledge (Table 5) shows that groups with strong links among each other, i.e., fishermen's groups, tend to have similar knowledge. The two categories not directly involved in marine resource extraction have a much poorer understanding of associated ecological components and processes, e.g., businessmen and farmers. The weak ties of the local businessmen to coastal resource extractors may explain their lack of ecological knowledge. As they are unlikely to acquire such knowledge through direct personal experience, this group is likely to remain with a poorer conception of resource status. However, the farmers are more closely connected to the resource extractors (Fig. 3), which may seem like a contradiction given their limited knowledge (Fig. 6). This may be explained by the fact that the group is very small, i.e., only eight individuals, and consequently their relations rather few, which means that the impact of each of their reported relations becomes statistically large. This makes the estimations of the strength of their relations with other groups somewhat unreliable.

Deep-sea fishermen's more holistic perception of the seascape could be attributable to their central position in the network. To some extent they share this perception with the middlemen, some of whom have acquired this broader seascape knowledge through personal experience, but more importantly through communication with all groups of fishermen as apparent in Fig. 3. Seine netters are, however, slightly more distanced, i.e., they have fewer ties to the tight cluster formed by middlemen, deep-sea, and gill net fishermen (Fig. 3). It is argued that tacit or complex knowledge transfer requires frequent and intense interactions (Hansen 1999, Reagans and McEvily 2003), thus, only fairly tight groups are likely to develop complex group-specific knowledge. If communication links are more diversely distributed among actors as observed among the other fishermen categories, the 
Fig. 3. Multidimensional scaling plot showing the social network structure of relations among groups based on predefined occupational categories. The size of each node is proportional to the group size, and the thickness of the links is proportional to the strength of the intergroup relations, i.e., the ratio of the observed vs. the expected number of relations. Thin line $<0.5$, medium line $<1$, thick line $>1$. Worth noting is that no direct exchange between fisher categories Seine net and Gill net occurs.

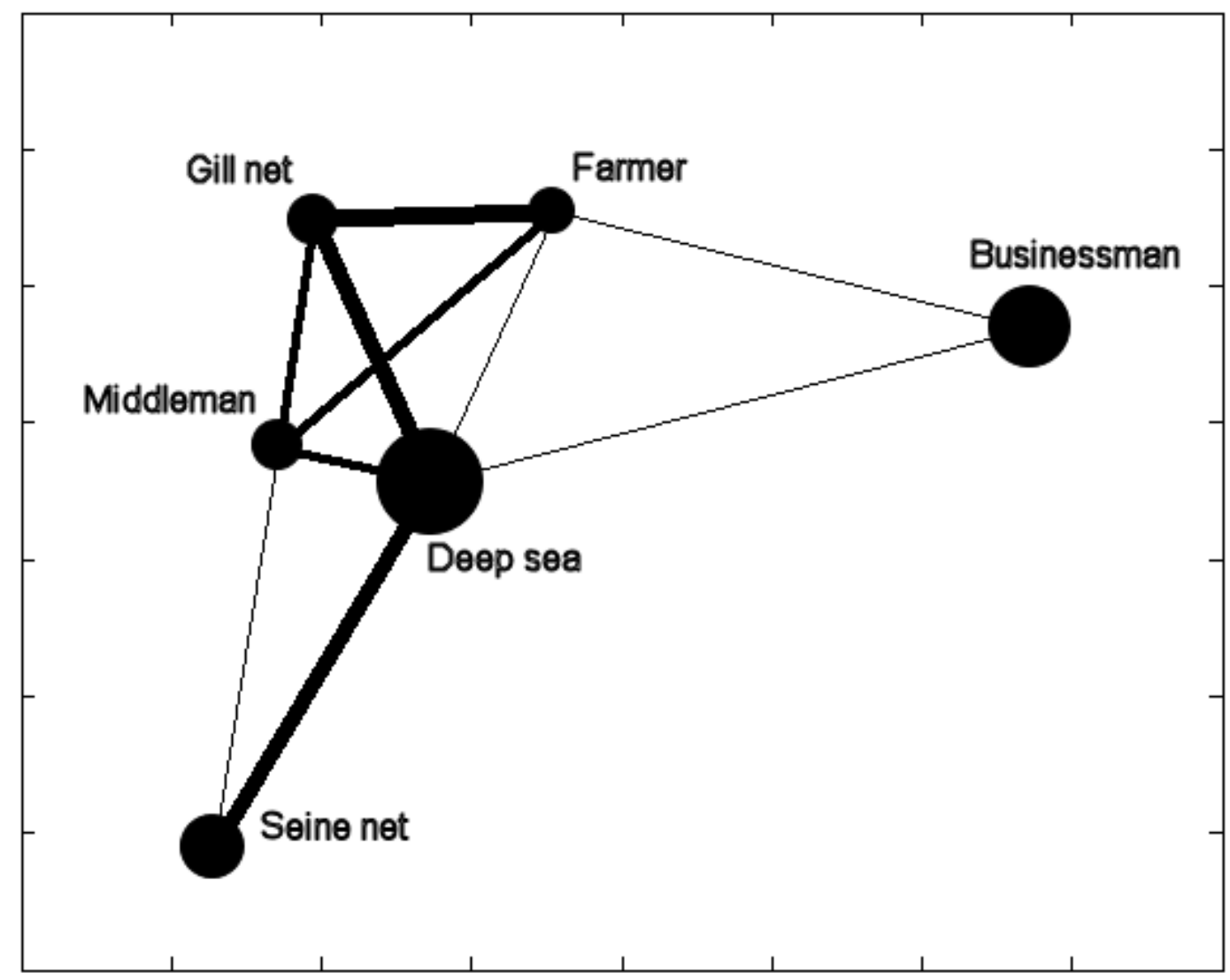

possibility to maintain group-specific knowledge is reduced. In fact, seine net fishermen report that approximately two out of three relations are with other seine netters (Table 2), and of those few outbound relations, most are only with deep-sea fishermen. This can explain why certain groupspecific knowledge related to linkages between seagrass variations, sea urchin abundance, and fish stocks is still maintained within the group of seine netters.
While outlining this agreement between knowledge distribution and network structure, we feel it is necessary to mention the inherent problem of causality in network analysis, which relates to the need for longitudinal data to verify changes in dependent variables following changes in the network structure. Although static, the analysis presented here does in fact show a fair correlation between the two, and our continued discussion will focus on implications of this, regardless of causality. 
Fig. 4. Multidimensional scaling plot of group structure based solely on relations reported by respondents. The position of each individual node is estimated based on both within-group relations as well as relations to other individuals outside the individual's own group. Groups are distinguishable as spatially clustered sets of nodes. Colors indicate the occupational category of each individual.

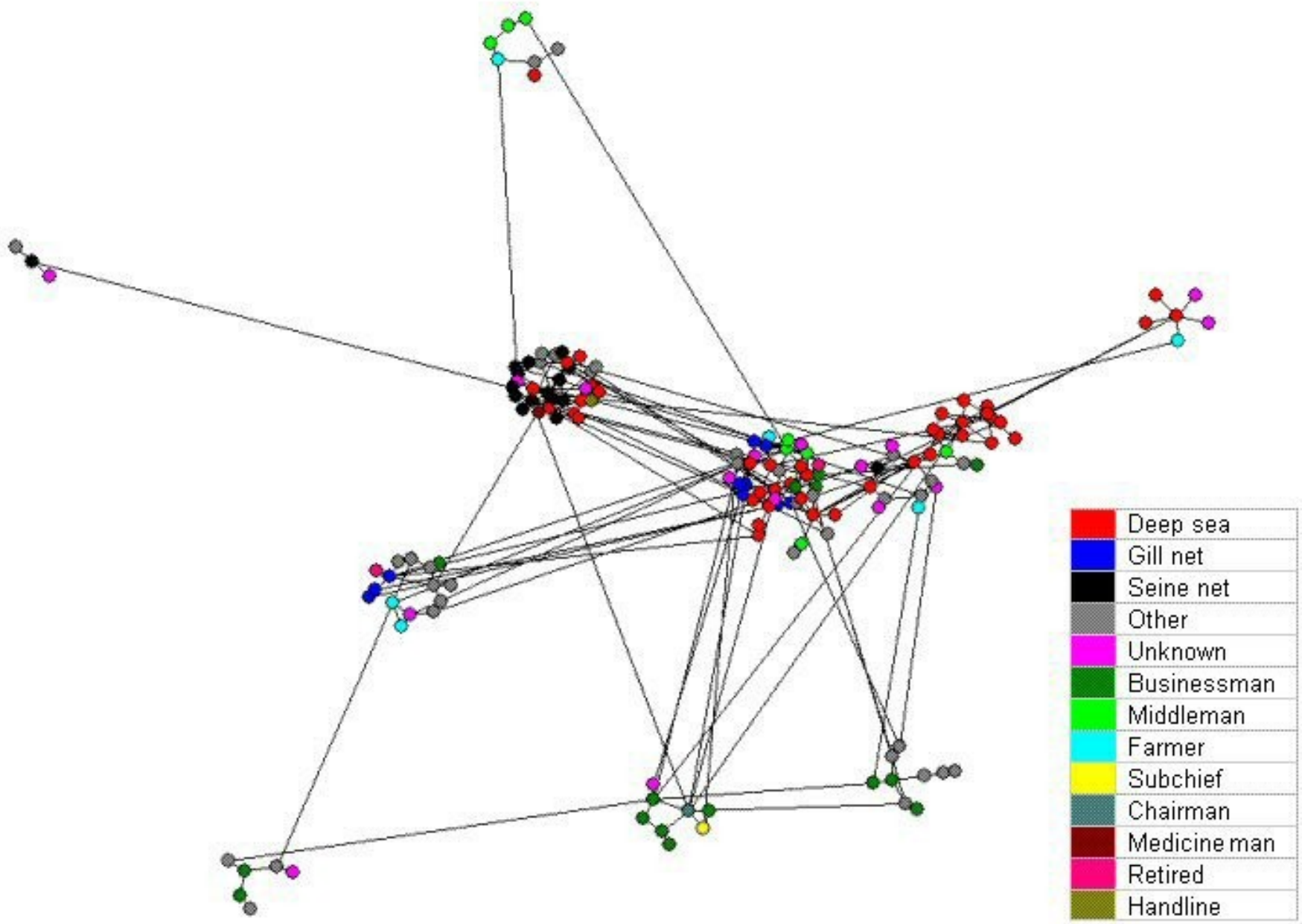

Our data does not allow us to differentiate in detail between different sources of LEK. Therefore, we cannot determine the extent to which observed similarities in knowledge among different groups are caused by similar experiences or by intergroup exchange of information and knowledge. We are, however, convinced that the observed distribution of knowledge cannot be adequately explained without considering the effect of the social network structure based on the discussion above (see also Reagans and McEvily 2003 and references therein).

\section{Prerequisites for collective action}

The community in focus has not initiated any collective action to reduce fishing pressure or use of destructive gear. This is due, in part, to a lack of empowerment of the community vis à vis the government with regard to management of natural resources. However, we propose that observed network structures may also serve as an explanation. The groups most centrally positioned in the network (see Figs. 3 and 4), and also most knowledgeable in the village are those represented by deep-sea 
Fig. 5. Values of the Modularily plotted vs. the number of groups for all hierarchical levels using the Community structure method (Newman and Girvan 2004). Dots refer to the Modularity calculated from 100 randomly generated networks with the same number of nodes and links as the observed real-world social network. Crosses represent the calculated level of Modularity for the observed network.

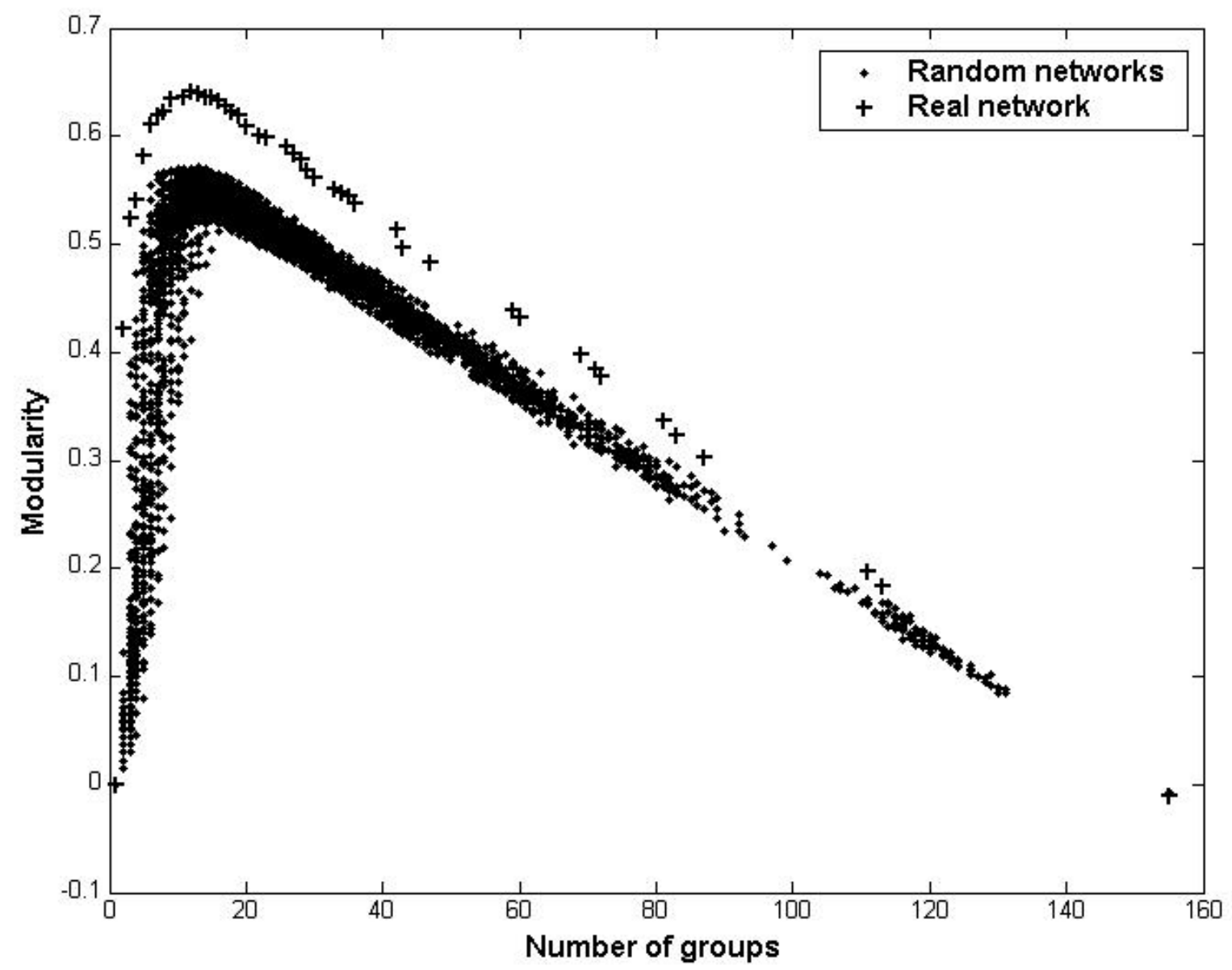

fishermen, many of whom are migrant fishermen returning to Tanzania during seasons of low fishing activity. The nature of the deep-sea fishing technique, using large boats, also makes this category of fishermen less confined to the immediate seascape adjacent to the village, allowing them to target pelagic stocks that are less vulnerable to overfishing on a local scale. Consequently, in their view, catches have not changed significantly, which may have reduced their perception of the fishery as overexploited, at least in relation to their own operations (Crona
2006). Perceptions of overexploitation as a general problem were vague. This, in combination with their migrant status, reducing their sense of place, affects motivation and makes deep-sea fishermen less likely to instigate action to regulate fishing activities. Thus, the group structurally best positioned does not take advantage of this to initiate collective action, whereas other groups, perhaps more willing to initiate action, are potentially not able to do so due to their less favorable network positions. 
Table 4. Cross-table of occupational and relational groups. The values represent the count of individuals for each combination. The $P$-value assuming no interaction between occupation and group membership $>$ 0.0001 . Absolute values of adjusted standardized residuals $\geq 2.0$ are an indication of a significant interaction between membership in the relational group and the occupational category, and are marked with a plus or a minus sign. Plus signs indicate an overrepresentation of a particular occupational category in a relation group, whereas the opposite applies for minus signs. $\mathrm{O}=$ Other, $\mathrm{BM}=$ Businessman, $\mathrm{F}=\mathrm{Farmer}, \mathrm{MM}=$ Middleman, $\mathrm{GN}=$ Gill Net fisherman, $\mathrm{DS}=$ Deep Sea fisherman, and $\mathrm{S}=$ Seine Net fisherman.

\begin{tabular}{|c|c|c|c|c|c|c|c|c|}
\hline \multirow{2}{*}{$\begin{array}{l}\text { Relational } \\
\text { group index }\end{array}$} & \multicolumn{8}{|c|}{ Occupational groups } \\
\hline & $\mathbf{O}$ & $\mathbf{B M}$ & $\mathbf{F}$ & MM & GN & DS & $\mathbf{S}$ & Total \\
\hline 1 & 2 & 0 & 1 & 0 & 0 & 3 & 0 & 6 \\
\hline 2 & 2 & 0 & 1 & $3(+)$ & 0 & 1 & 0 & 7 \\
\hline 3 & 2 & 0 & 0 & 0 & 0 & 0 & 1 & 3 \\
\hline 4 & 8 & 3 & 1 & 3 & $7(+)$ & 8 & $0(-)$ & 30 \\
\hline 5 & 6 & $3(+)$ & 0 & 0 & 0 & 0 & 0 & 9 \\
\hline 6 & 9 & $0(-)$ & 0 & 0 & 0 & 9 & $14(+)$ & 32 \\
\hline 7 & 3 & $5(+)$ & 0 & 0 & 0 & 0 & 0 & 8 \\
\hline 8 & 9 & 1 & 2 & 0 & $3(+)$ & $0(-)$ & 0 & 15 \\
\hline 9 & 8 & 0 & 1 & 0 & 0 & 3 & 1 & 13 \\
\hline 10 & 4 & 2 & 0 & 0 & 0 & 0 & 0 & 6 \\
\hline 11 & $1(-)$ & 1 & 0 & 1 & 0 & $12(+)$ & 0 & 15 \\
\hline 12 & 4 & 0 & 0 & 1 & 0 & $6(+)$ & 0 & 11 \\
\hline Total & 58 & 15 & 6 & 8 & 10 & 42 & 16 & 155 \\
\hline
\end{tabular}

In addition, some occupational categories, e.g., businessmen, are little involved in the knowledge and information exchange regarding natural resources. Even though they could be instrumental in enabling collective action through their ties to village committees and other institutional hierarchies (cf., Krishna 2002), their lack of knowledge and access to information on resource status is likely to negatively affect their incentive to engage in collective action initiatives.

\section{Centrality or complexity: the lack of an} optimal network structure

Social networks are increasingly cited as instrumental in enabling communities to adaptively respond to environmental change and to initiate and sustain successful co-management of natural resources (Olsson 2004a, Tompkins and Adger 2004), but the precise mechanisms by which this happens are rarely discussed. Nonetheless the field of sociology is ripe with examples showing how structures of social networks are crucial for understanding and explaining social phenomena 
Table 5. Summary of local ecological knowledge of different occupational groups in the target community, Kenya. Species refer to marine species of fish and shellfish targeted by categories of fishermen. For each species the functional groups to which it belongs, based on trophic level, is indicated in brackets; Pelagic/ demersal predator, (P) Benthic predator, (BP) Herbivores, (H) Planktivores, (Pl) Omnivores (O).

\section{Occupational category Species}

Deep sea

Gill net

Farmers

Businessmen

Seine net

Middlemen

(BP)

\section{Ecological links and processes}

\author{
Caesio sp. (Pl) \\ Carangidae (P) \\ Hyporamphus sp. (O) \\ Lethrinus sp. (BP) \\ Scombridae (P) \\ Selar sp. (P) \\ Siganus sp. $(\mathrm{H})$ \\ Squid (P)
}

Carangidae (P)

Caranx sp. (P)

Lethrinus sp. (BP)

Lutjanus argentimaculatus

Mugilidae (H)

Pomadasys sp. (BP)

Scombridae (P)

Selar sp. (P)

Sphyraena sp. (P)

Squid (P)

Strongylura sp. (P)

Chanos chanos $(\mathrm{O})$
Gerres sp. $(B P)$
Lethrinus harak (BP)
Mugilidae (H, $\mathrm{P})$
Siganus sp. $(\mathrm{H})$
Sphyraena sp. $(\mathrm{P})$
Strongylura sp. (P)
- Notion of regional fish stock migrations at a local and regional scale - Seasonal monsoon related wind patterns and currents affect fish migrations along the regional coastline

- Notion that changes in climate, timing of the monsoon rains, and $\mathrm{El}$ Niño phenomena have occurred recently resulting in an effect on the artisanal shrimp fishery as well as mangrove coverage

- Recognition of links between the ecosystems mangroves, seagrasses, and reef

- Notion of regional fish stock migrations at a local scale - Seasonal monsoon related wind patterns and currents affect fish migrations along the regional coastline

- Notion that changes in climate, timing of the monsoon rains, and El Niño phenomena have occurred recently resulting in an effect on the artisanal shrimp fishery as well as mangrove coverage - Notion that sea urchin aggregations can affect the dynamics of seagrass meadows and associated fauna

- Notion that changes in climate, timing of the monsoon rains, and El Niño phenomena have occurred recently resulting in an effect on the artisanal shrimp fishery as well as mangrove coverage - Seasonal monsoon related wind patterns and currents affect fish migrations along the regional coastline

- Notion of regional fish stock migrations

- Seasonal monsoon related wind patterns and currents affect fish migrations along the regional coastline

- Recognition of interlinkages between seascape components

- Poor general knowledge of all ecological links and processes in the seascape

- Poor general knowledge of all ecological links and processes in the seascape 
Fig. 6. Relative difference in local ecological knowledge among different occupational groups operating in the target community. Knowledge is divided into three categories based on the three recognized subcomponents of the coastal seascape: mangrove, seagrass, and reef. Knowledge of different groups for each subcomponent is represented as the relative difference of their level of knowledge compared to an estimated average level of knowledge for all groups, i.e., the baseline in the figure. Thus, the bars represent each group's knowledge in relation to other groups. Amount of knowledge, for each occupational category, is ranked based on the expressed level of detail of ecological components and processes (adapted from Crona 2006).

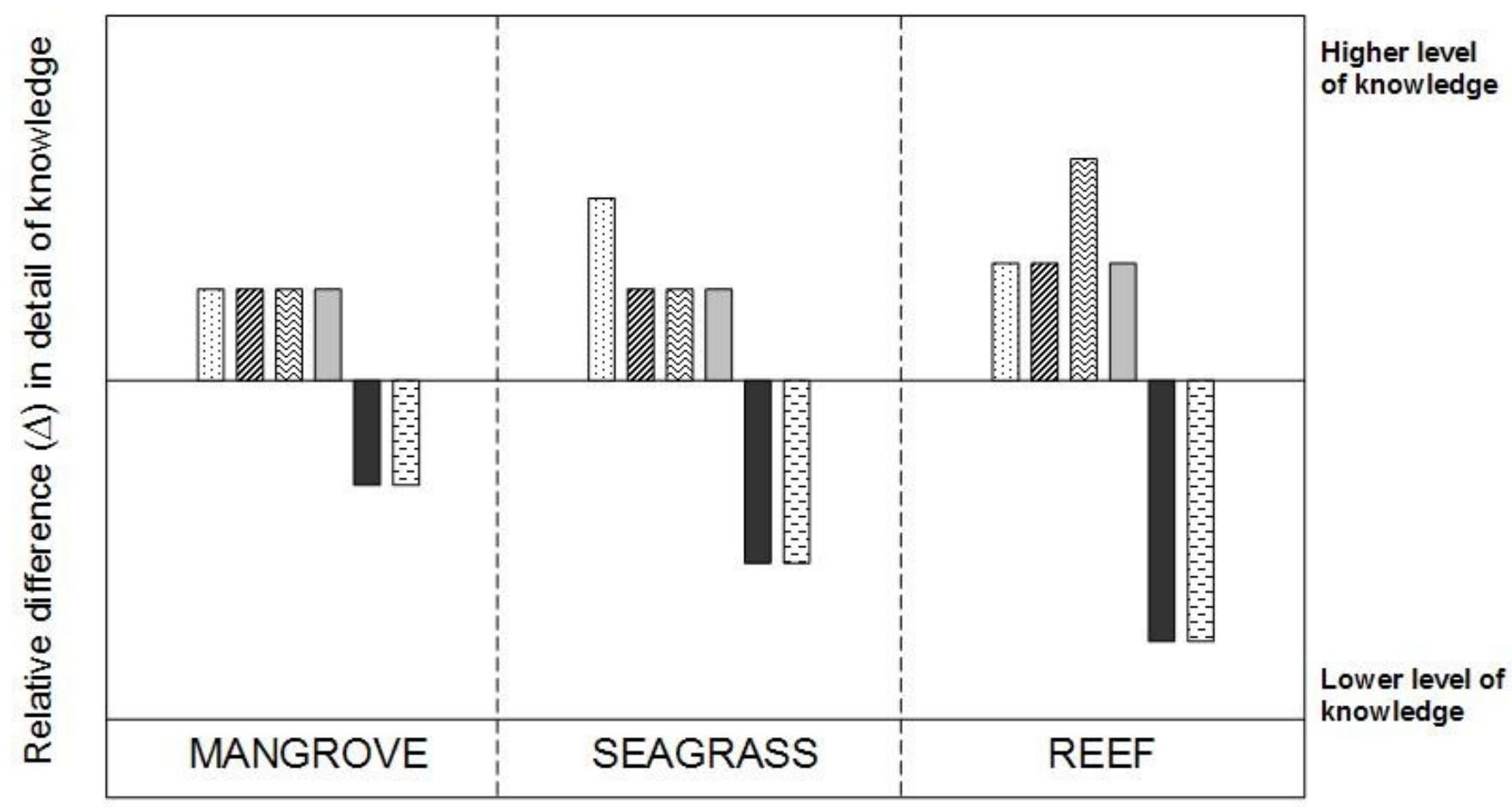

$\begin{array}{llll}\square & \text { Seine net } & \square & \text { Gill net } \\ \text { WIA } & \text { Middlemen } & \square & \text { Farmers } \\ \text { 兹 } & \text { Deep sea } & \text { B } & \text { Businessmen }\end{array}$

(Wasserman and Faust 1994). For example, social psychologists have shown that centralized networks perform simple tasks more efficiently than do decentralized ones when one or just a small cluster of actors are very centrally positioned in the network, leaving the others in the periphery (Leavitt 1951, Shaw 1981). However, they also showed that decentralized structures perform better when tasks are complex. This is attributed to the contribution from all members to a solution, providing diversity of information and knowledge in solving the problem. Environmental management must, in many respects, be considered a complex task, with complex chains of cause and effect in ecological systems. It is therefore likely that less centralized network structures are preferred for long-term management of ecosystems. However, centralized structures in resource management play an important role in mobilizing and coordinating human resources for collective action; an argument 
Table 6. Summary of local ecological knowledge common to all studied occupational groups in the target community, Kenya.

\begin{tabular}{ll}
\hline \hline Ecological component & Ecological links and processes \\
\hline Mangroves & $\begin{array}{l}\text { - Knowledge of the central function of mangroves in coastal biological, hydrological, and } \\
\text { geomorphologic processes in the form of nursery habitats, water filtration, and sediment } \\
\text { stabilization } \\
\text { - Awareness of the nursery function provided by mangroves for fish and shellfish residing } \\
\text { part of their life outside of the mangrove habitat; Shows a notion of the positive spillover } \\
\text { effect of such functions on coupled ecological subsystems such as seagrass beds and coral } \\
\text { reefs }\end{array}$ \\
& $\begin{array}{l}\text { - Acknowledgement that historical and present land uses, such as mangrove cutting, will } \\
\text { cause changes in the distribution and abundance of associated species, e.g., crabs, shrimp, } \\
\text { fish, and ecosystem functions such as soil stabilization, water movement, nursery habitats, } \\
\text { nesting areas, and wind breakers }\end{array}$ \\
& - Acknowledgement that seasonal climatic changes affect the distribution and abundance of \\
shrimp and finfish in the area: & seasonal monsoons and the resulting freshwater outflow attract juvenile shrimps into the \\
mangrove system
\end{tabular}

${ }^{a}$ knowledge poor among farmers and businessmen

upon which our previous discussion relies. In Kristianstad, for example, Olsson et al. (2004b) showed that in the initial phase of building consensus and amassing support for collective action around the management of the wetland, a network centered on a few highly active individuals laid the ground to what has emerged as a seemingly successful collaboration among stakeholder groups in the area. These findings are in line with the effectiveness of centralized structures for coordination and dissemination of information shown by Leavitt (1951).

The inevitable conclusion is, thus, that different network structures have features that affect the social dynamics judged important for successful adaptive co-management differently. Finding one optimal network structure is unlikely, as optimization of structure seems related to the phase of the management process. For example, high centralization may be beneficial during the initiation phase to coordinate and instigate collective action. Decentralization, on the other hand, may provide access to the diversity of information from different groups, which is needed for sustainable management in the long term. A potentially fruitful path is to look at the social network structures that exist within a given community and analyze structural characteristics such as the tendency for multiple group formation (c.f., Fig. 4). Guided by evidence of the effects that these structural characteristics may have on coordination of initiatives, consensus building, and information/ knowledge transfer, management strategies can be designed to maximize the potential of a certain structure and include elements to minimize its drawbacks.

\section{CONCLUSION}

Social networks are increasingly cited as instrumental in enabling communities to adaptively respond to environmental change and to initiate and sustain successful co-management of natural resources. Here, we have started to investigate the precise mechanisms by which this may occur.

This study identifies a distinct pattern of correlation between the distribution of local ecological knowledge (LEK) held by resource users and the social network for communication of resource 
related knowledge and information. Fishermen, in spite of using different gear types and fishing in different areas, tend to have similar knowledge; a fact that may be attributed to their relatively frequent relations. On the other hand, the weak ties between fishermen and nonfishermen may be one factor explaining the latter's lack of ecological knowledge. At a more detailed level, it is shown that geardefined occupation plays an important role in defining resource-related communication structures, indicating that fishermen are, in fact, not a homogenous stakeholder group, but consist of a number of subgroups communicating primarily with members of their own occupational category. This pattern of subgroups is also qualitatively shown to correlate with variations of fishermen's LEK.

Our results demonstrate that structures in relational networks are important for identifying central and potentially influential actors. They also indicate that incentives and attributes, enabling these actors to emerge as leaders and coordinate and instigate collective action, are essential for successful comanagement. Without the appropriate incentives and knowledge, favorably positioned actors will not exploit their positions to initiate collective action. In this study, this was exemplified by the centrally positioned group of deep-sea fishermen who have not taken any initiatives to regulate resource extractions. As such, they may in fact act as barriers for collective action since highly motivated, but less central actors, have difficulty initiating action due to less favorable positions. Furthermore, potentially influential actors, here represented by local businessmen, are loosely tied to the communication network of resource extractors. Thus, their lack of knowledge and access to information on resource status is likely to negatively affect their incentive to engage in collective action initiatives even though they could play an instrumental role through their ties to village committees and other institutional hierarchies.

Although our current study is limited to a rural village in Kenya, we believe that our results are potentially applicable over a larger scale. Small fishing communities, largely dependent on direct resource extraction, are a common feature of many third world countries, and the cultural setting in which they are embedded is likely to be similar, at least along the Swahili section of the East African coast.
We conclude that social network analysis is a valuable tool for identifying de facto social groups, influential actors, and patterns of communications, but should be combined with identification of incentives and attributes that could enable potentially influential actors to emerge as leaders, coordinating and instigating collective action essential for successful co-management. Moreover, even though the distribution of LEK seems related to the network structure, there is a need to further investigate how this may affect possibilities for collective action and co-management of natural resources. The formal institutional setup, which in part discourages local initiatives, may to some extent explain the overexploitation of the fishing resources in our study area. However, we hypothesize that the lack of collective action to remedy this unsustainable situation may also be attributed to the differences in resource knowledge among the villagers, a difference seemingly correlated with the structures of the social networks in the community.

\section{LITERATURE CITED}

Abrahamson, E., and L. Rosenkopf. 1997. Social network effects on the extent of innovation diffusion: a computer simulation. Organization Science 8(3):289-309.

Becker, C. D., and K. Ghimire. 2003. Synergy between traditional ecological knowledge and conservation science supports forest preservation in Ecuador. Conservation Ecology 8(1).

Borgatti, S. P., M. G. Everett, and L. C. Freeman. 2002. Ucinet for Windows: software for social network analysis. Analytic Technologies, Harvard, Massachusetts, USA.

Buck, L. E., C. C. Geisler, J. Schelhas, and E. Wollenberg, editors. 2001. Biological diversity: balancing interests through adaptive collaborative management. CRC Press, New York, New York, USA.

Carlsson, L., and F. Berkes. 2005. Comanagement: concepts and methodological implications. Journal of Environmental Management 75:65-76.

Carpenter, S., B. Walker, J. M. Anderies, and N. Abel. 2001. From metaphor to measurement: 
resilience of what to what? Ecosystems 4 (8):765-781.

Cooley, C.H.1909. On selfand socialorganization. The University of Chicago Press, Chicago, Illinois, USA.

Crona, B. I. 2006. Supporting and enhancing development of heterogeneous ecological knowledge among resource users in a Kenyan seascape. Ecology and Society 11(1).

Cross, R., S. P. Borgatti, and A. Parker. 2001. Beyond answers: dimensions of the advice network. Social Networks 23(3):215-235.

Dahdouh-Guebas, F., C. Mathenge, J. G. Kairo, and N. Koedam. 2000. Utilization of mangrove wood products around Mida Creek (Kenya) amongst subsistence and commercial users. Economic Botany 54(4):513-527.

Davis, A., and J. R. Wagner. 2003. Who knows? On the importance of identifying 'experts' when researching local ecological knowledge. Human Ecology 31(3):463-489.

Festinger, L., S. Schachter, and K. Back. 1950. Social pressures in informal groups: a study of human factors in housing. Harper and Brothers, New York, New York, USA.

Folke, C., S. Carpenter, B. Walker, M. Scheffer, T. Elmqvist, L. Gunderson, and C. S. Holling. 2004. Regime shifts, resilience, and biodiversity in ecosystem management. Annual Review of Ecology, Evolution, and Systematics 35(1):557-581.

Frank, K. A. 1996. Mapping interactions within and between cohesive subgroups. Social Networks 18(2):93-119.

Freeman, L. C. 2004. The development of social network analysis: a study in the sociology of science. Empirical Press, Vancouver, British Columbia, Canada.

Gadgil, M., P. R. S. Rao, G. Utkarsh, P. Pramod, and A. Chhatre. 2000. New meanings for old knowledge: the People's Biodiversity Registers program. Ecological Applications 10(5):1307-1317.

Ghimire, S. K., D. McKey, and Y. AumeeruddyThomas. 2004. Heterogeneity in ethnoecological knowledge and management of medicinal plants in the Himalayas of Nepal: implications for conservation. Ecology and Society 9(3).

Girvan, M., and M. E. J. Newman. 2002. Community structure in social and biological networks. Proceedings of the National Academy of Sciences of the United States of America 99 (12):7821-7826.

Glaesel, H. 2000. State and local resistance to the expansion of two environmentally harmful marine fishing techniques in Kenya. Society and Natural Resources 13:321-338.

Gould, R. V., and R. M. Fernandez. 1989. Structure of mediation: a formal approach to brokerage in transactions networks. Sociological Methodology 19:89-126.

Granovetter, M. 1973. The strength of weak ties. American Journal of Sociology 76(6):1360-1380.

Haberman, S. J. 1978. Analysis of quantitative data: Volume 1. Introductory topics. Academic Press, New York, New York, USA.

Hansen, M. T. 1999. The search-transfer problem: the role of weak ties in sharing knowledge across organization subunits. Administrative Science Quarterly 44:82-111.

Holling, C. S. 1978. Adaptive environmental assessment and management. John Wiley and Sons, New York, New York, USA.

Homans, G. C. 1950. The human group. Routledge and Kegan Paul, London, UK.

Hunn, E. S., D. R. Johnson, P. N. Russel, and T. F. Thornton. 2003. Huna Tinglit traditional environmental knowledge, conservation, and the management of a 'wilderness' park. Current Anthropology 44(Supplement):S79-S103.

Johannes, R. E. 1981. Word of the lagoon: fishing and marine lore in the Palau district of Micronesia. University of California Press, London, UK.

Johannes, R. E. 1998. The case for data-less marine resource management: examples from tropical nearshore fisheries. Trends in Ecology and Evolution 13:243-246. 
Kadushin, C. 1966. The friends and supporters of psychotherapy: on social circles in urban life. American Sociological Review 31:786-802.

Krackhardt, D., and R. N. Stern. 1988. Informal networks and organizational crisis: an experimental simulation. Social Psychology Quarterly 51 (2):123-140.

Krishna, A. 2002. Active social capital: tracing the roots of development and democracy. Columbia University Press, New York, New York, USA.

Leavitt, H. 1951. Some effects of certain communication patterns on group performance. Journal of Abnormal and Social Psychology 46:38-50.

Marsden, P. V. 1990. Network data and measurement. Annual Review of Sociology 16:435-463.

McClanahan, T. R., H. Glaesel, J. Rubens, and R. Kiambo. 1997. The effects of traditional fisheries management on fisheries yields and the coral-reef ecosystems of southern Kenya. Environmental Conservation 24(2):105-120.

Moller, H., F. Berkes, P. O'Brian Lyver, and M. Kislalioglu. 2004. Combining science and traditional ecological knowledge: monitoring populations for co-management. Ecology and Society 9(3).

Morgan, D. L. 1998. Planning focus groups. Sage, London, UK.

Newman, M. E. J., and M. Girvan. 2004. Finding and evaluating community structure in networks. Physical Review E 69(2).

Nygren, A. 2005. Community-based forest management within the context of institutional decentralization in Honduras. World Development 33(4):639-655.

Obura, D. O., I. N. Wanyoni, and J. M. Mwaura. 2002. Participatory monitoring of an artisanal fishery in Kenya. Pages 70-82 in O. Lindén, D. Souter, D. Wilhelmsson, and D. Obura, editors. Coral reef degradation in the Indian Ocean. Status Report 2002. University of Kalmar, Cordio, Sweden.
Ochiewo, J. 2004. Changing fisheries practices and their social implications in south coast Kenya. Ocean and Coastal Management 47:389-408.

Olsson, P., C. Folke, and F. Berkes. 2004a. Adaptive comanagement for building resilience in social-ecological systems. Environmental Management 34(1):75-90.

Olsson, P., C. Folke, and T. Hahn. 2004b. Socialecological transformation for ecosystem management: the development of adaptive co-management of a wetland landscape in southern Sweden. Ecology and Society 9(4).

Ostrom, E. 2005. Understanding institutional diversity. Princeton University Press, Bloomington, Indiana, USA.

Reagans, R., and B. McEvily. 2003. Network structure and knowledge transfer: the effects of cohesion and range. Administrative Science Quarterly 48(2):240-267.

Scheffer, M., S. Carpenter, J. A. Foley, C. Folke, and B. Walker. 2001. Catastrophic shifts in ecosystems. Nature 413:591-596.

Schneider, M., J. Scholz, M. Lubell, D. Mindruta, and M. Edwardsen. 2003. Building consensual institutions: networks and the National Estuary program. American Journal of Political Science 47 (1):143-158.

Scott, J. 2000. Social network analysis: a handbook. Second edition. Sage, London, UK.

Shaw, M.E. 1981. Group dynamics: the psychology of small group behavior. Third edition. McGrawHill, New York, New York, USA.

Tompkins, E. L., and W. N. Adger. 2004. Does adaptive management of natural resources enhance resilience to climatic change? Ecology and Society 9(2).

Walker, B., S. Carpenter, J. M. Anderies, N.Abel, G. Cumming, M. A. Janssen, L. Lebel, J. Norberg, G. Peterson, and R. Pritchard. 2002. Resilience management in social-ecological systems: a working hypothesis for a participatory approach. Conservation Ecology 6(1).

Wasserman, S., and K. Faust. 1994. Social 
network analysis methods and applications. Cambridge University Press, Cambridge, UK.

Weimann, G. 1982. On the importance of marginality: one more step into the two-step flow of communication. American Sociological Review 47(6):764-773.

Responses to this article can be read online at:

http://www.ecologyandsociety.org/voll1/iss2/art7/responses/

\section{Acknowledgments:}

We would like to thank all respondents for participating in this study as well as Abdul Rashid for tireless work and organization in the field. This study would not have been possible without him. We also thank Lennart Bodin for assistance with some of the statistics, and Elinor Ostrom for providing valuable suggestions at an initial phase of the project. The study was conducted with financial support from SIDA (Swedish International Development and Aid). Gratitude is also extended to Kenya Marine and Fisheries Research Institute to which one of the authors (B. Crona) is affiliated. Finally, we also thank Jon Norberg, Thomas Elmqvist, and two anonymous reviewers for helpful comments on earlier versions of this manuscript. 


\section{APPENDIX 1. Data collection Local Ecological Knowledge (LEK)}

Seven different occupational categories were identified; businessmen (local entrepreneurs), middlemen and five occupational categories of fishermen defined based on primary gear type and fishing technique. Businessmen is a rather broad occupational category, which was defined based on a description by respondents of their livelihood as selling and/or buying any kind of goods such as food, groceries, building material and related services. Middlemen is the local term used for fishmongers, persons who buy fish from the fishermen directly at the landing sites and sell it on to a third party. Because their business is purely focused on fish they were distinguished from other businessmen. Those respondents who did not qualify into any of the above categories were classified as "Others". This category included basically all activities that did not sort under the above mentioned categories and ranged from driving local taxis and commuting buses to washing clothes or doing temporary construction work. This division was based on the assumption that people trading services are likely to be more decoupled from the natural resource base. A small number of categories were represented by only one individual but were judged to be sufficiently influential in the community and thus distinguished (e.g. medicine man, chairman, sub-chief). The category "Unknown" included individuals that were either not interviewed, retired or could not be classified.

A semi-structured interview guideline was used based on the approach described by Morgan (1998) and is presented below.

\section{Interview guideline}

Introduction

Q: Let me ask, are you all from \#village name\#? (Respondents were asked to state their names, where they live, and for how long)

Q: How long have you been fishing (farming, doing business etc) in this area?

Q: Could you tell me a little about how and why each of you became a fisherman? (The question was asked to give a brief personal history of each group member)

Depending on the answers this was followed up with...

Q: Is that a common way of entering the profession?

Q: Does this mean that your sons/children will become fishermen as well? (The question was asked to give an indication of a potential changes in traditions, knowledge transfer and young people moving from village)

Q: How will all the knowledge you have be passed on to younger generations?

Q: Do you feel confident that the knowledge will be kept this way?

$\mathrm{Q}$ : Is it important that such knowledge is maintained and passed on to younger generations?

Topic 1- Knowledge of species and ecological processes in the bay

Q: Did you get a good catch today? What did you catch?

Q: Do you always catch this type of fish? If not what else do you normally catch? (A discussion around a representative composition of catch in terms of different species)

Q: Respondents were asked to identify the 10-15 most important fish species they catch taking into consideration the anticipated price at sale, the perceived abundance and the proportional importance of the species to their daily catch.

Q: Out of these 10-15, which 5 species do you judge to be the most important?

Q: Could you explain to me how the catch changes over the course of the year, from season to season, fort each of these five taxa/species? Q: For each of the 5 taxa/species:

- Where do you catch it? At what time/season? Why?

- Are they adults?

- What about when they are young, where can you find them? Why?

- What do these fish eat at different stages of their life?

At this point the group was asked to draw a rough map of the area together with the interviewer. Specific sites and characteristic features on the map were discussed to ensure that the interviewer's perception of the area map agreed with the one held by the group. All group members were encouraged to get involved in the process. The map was then used to indicate primary target areas for the taxa/species identified in the previous questions.

Q: Do you use any bate when fishing? Where does it come from and how/why?

Q: Respondents were asked to identify 3 taxa/species of fish that they associate primarily with A) mangroves B) sea grass beds C) reefs. (This question was used partly as a validation tool for knowledge of target species above but also as a measure of the how easily respondents of non-fisher categories could differentiate between fish taxa associated with different sub-systems of the coastal seascape)

Throughout the above discussion respondents were probed for clarifications and further explanations wherever appropriate and needed.

\section{Shrimps}

Q: Do shrimps come in the mangroves?

Q: If so why are they found in the mangroves?

Q: Are they big or small when they come in?

Q: Where (in the bay) are shrimps caught? Why?

\section{Crabs}

Q: Where do they live? And why?

Q: Do they live their whole life there? Explain. (The question was asked to reveal knowledge of the crab life cycle). 
Q: What do you think would happen if most of the mangroves around the bay were cut down? Would it have any effect on the fisheries? If so, how? Do you know of any other effects of mangrove deforestation?

Topic 2- Acknowledgment of changes in the ecosystem over time and understanding of ecological processes and links among components in the system

Q: You say you have been fishing in the area for X years, have you noticed any changes in the type of fish/shrimps/crabs you catch or the area where fish/shrimp/crabs are caught?

Using of the map drawn previously to explain changes and patterns the following questions were asked:

Q: Have you perceived any change in mangrove coverage over the years? A discussion about coverage before, during and after the change (historical events were used to place the change in time). Respondents were asked to explain the process of change by drawing a time line indicating patterns of increasing and decreasing coverage over time.

Q: Have you perceived any change in catches over the years? Respondents were asked to identify any changes in fish catches over time by drawing a time line (with assistance from the interviewer and moderator) and indicating patterns of increasing and decreasing catches over time.

Q: Can you tell me what you think may be the reason for this change?

Q: What solutions/actions can you suggest to improve the situation? (This was asked in order to further identify coupled social-ecological knowledge and ideas, i.e. recognition of institutional/organizational change needed for resource management)

Throughout the above discussion specific questions to follow up issues of importance were incorporated under each topic.

\section{Literature Cited}

Morgan, D. L. 1998. Planning Focus Groups. Sage Publications Inc., London. 